\title{
Subretinal injection of amyloid- $\beta$ peptide accelerates RPE cell senescence and retinal degeneration
}

\author{
CHAOQI LIU* , LINING CAO*, SHUAI YANG, LINXINYU XU, PEI LIU, FANG WANG and DING XU \\ Department of Ophthalmology, Shanghai Tenth People's Hospital Affiliated to Tongji University \\ School of Medicine, Shanghai 200072, P.R. China
}

Received July 2, 2014; Accepted October 30, 2014

DOI: $10.3892 /$ ijmm.2014.1993

\begin{abstract}
Drusen are considered a hallmark characteristic of age-related macular degeneration (AMD). In our previous study, we found that amyloid- $\beta$ (A $\beta$ ) peptide, a component of drusen, induced the cells of the retinal pigment epithelium (RPE; RPE cells) to enter senescence; however, its effects in vivo remain unknown. Thus, the present study was carried out to explore the in vivo effects of $\mathrm{A} \beta$ peptide on RPE cell senescence and senescence-associated inflammation in C57BL/6 mice. C57BL/6 mice received a subretinal injection of $A \beta(1-42)$ peptide; on day 7 post-injection, the mice were anesthetized and subjected to whole-body perfusion with $4 \%$ paraformaldehyde (PFA) in PBS and the whole eyes were then enucleated. Retinal function was assessed by electroretinography (ERG), and the morphological characteristics of the retina were examined by light and electron microscopy. Fundus autofluorescence (FAF) was examined by confocal scanning laser ophthalmoscopy (cSLO). The expression of $\mathrm{p} 16^{\mathrm{INK} 4 \mathrm{a}}$, a marker of cellular senescence, was examined by immunofluorescence staining and western blot analysis. The RPE-choroid was analyzed for cytokine expression by RT-PCR. In A $\beta(1-42)$-injected mice, scotopic ERG responses declined. Degenerative alterations, including the disruption of the inner segment (IS)/outer segment (OS) junction and extensive vacuolation and thickness of Bruch's membrane (BrM) were observed under a a light microscope. The accumulation of vacuoles and the loss of basal infoldings in the RPE were identified using an electron microscope. FAF and $\mathrm{p}^{\mathrm{INK} \mathrm{INa}^{\mathrm{N}}}$ expression increased in $\mathrm{A} \beta(1-42)$-injected mice. In addition, $A \beta(1-42)$ upregulated interleukin (IL)- 6 and IL- 8
\end{abstract}

Correspondence to: Dr Fang Wang or Dr Ding Xu, Department of Ophthalmology, Shanghai Tenth People's Hospital Affiliated to Tongji University School of Medicine, 301 Middle Yan Chang Road, Shanghai 200072, P.R. China

E-mail: 18917683335@163.com

E-mail: daisyxu70@hotmail.com

*Contributed equally

Key words: age-related macular degeneration, inflammation, senescence, retinal pigment epithelium gene expression in the RPE-choroid. In conclusion, our results confirm the effects of $A \beta(1-42)$ peptide on RPE senescence in vivo. The $\mathrm{A} \beta$-injected mice developed $\mathrm{AMD}$-like ocular pathology. It is thus suggested that RPE cell senescence is a potential mechanistic link between inflammation and retinal degeneration.

\section{Introduction}

Age-related macular degeneration (AMD) is the leading cause of irreversible visual impairment among the elderly in western countries. AMD is primary characterized by the formation of drusen, which are extracellular deposits between the retinal pigment epithelium (RPE) and Bruch's membrane (BrM), containing glycolipids, proteins and cellular debris. The appearance of drusen is strongly correlated with the development of AMD $(1,2)$.

Amyloid- $\beta$ (A $\beta)$ peptide, a component of drusen, is considered to contribute to neurodegenerative events and/or chronic inflammation in the retina of patients with AMD. A $\beta$ deposition within the vesicles is particularly observed in the eyes of patients with advanced AMD $(3,4)$. It has been postulated that the presence of $A \beta$ triggers a local inflammatory response that activates the immune system. Several in vitro studies have demonstrated that inflammation pathways and immune response are significantly upregulated in A $\beta$-stimulated cells of the RPE (RPE cells) $(5,6)$. A single intravitreal injection of $\mathrm{A} \beta$ peptide has been shown to induce inflammasome activation in the retinas of rats (7). A recent clinical trial reported that RN6G, a humanized monoclonal antibody against $A \beta$, reduced the $A \beta$ deposits in the retina, thus preserving the retinal function of the animals and maintaining normal RPE morphology (8).

Chronic inflammation is associated with aging and plays an important role in AMD (9); however, the source of sterile inflammation that fuels retinal degeneration in AMD remains unknown. Age-related chronic inflammation may be derived from two sources: i) an age-related decline in homeostatic immune function, or ii) senescent cells. Cellular senescence may cause chronic inflammation through the senescence-associated secretory phenotype (SASP). SASP proteins include a wide range of chemokines and cytokines [interleukin (IL)-6, IL-8, IL-1, granulocyte-macrophage colony-stimulating factor, monocyte chemotactic protein (MCP) and matrix 
metalloproteinases (MMPs)] that are known to stimulate inflammation $(10,11)$. Cellular senescence is defined as a state of irreversible proliferative arrest caused by a wide range of stimuli, including severe DNA damage, the expression of oncogenes, oxidative stress and strong mitogenic signals (12-14). A $\beta$ has been recently been shown to be involved in the senescence of neuronal cells, astrocytes and endothelial cells (15-18). Our previous in vitro study demonstrated that $\mathrm{A} \beta$ peptide caused RPE cells to enter senescence (19). However, the in vivo effects of $A \beta$ peptide on RPE cell senescence and senescence-associated inflammation remain unclear.

The deposition of $A \beta$ peptide, astrocyte senescence and altered SASP expression have been observed in the brains of patients with Alzheimer's disease (AD) (17). This finding suggests the existence of a correlation between $A \beta$ peptide and senescenceassociated neuronal inflammation (17). Previous in vivo studies have demonstrated that the intravitreal or subretinal injection of $A \beta$ peptide may cause retinal degeneration and inflammation $(7,20)$. However, to the best of our knowledge, the effects of the subretinal injection of $A \beta$ peptide on RPE cell senescence have not been investigated to date. Thus, in the present study, we aimed to explore the role of cell senescence and inflammation in the retinal degeneration induced by $\mathrm{A} \beta(1-42)$ peptide.

\section{Materials and methods}

$A \beta(1-42)$ oligomerization. $\mathrm{A} \beta(1-42)$ peptide and its inactive reverse control peptide $A \beta(42-1)$ were prepared as described in our previous study (19). Briefly, $0.5 \mathrm{mg}$ of lyophilized $\mathrm{A} \beta$ peptide (Sigma-Aldrich, Shanghai, China) was dissolved in $140 \mu \mathrm{l}$ hexafluoroisopropanol (HFIP) and incubated for $20 \mathrm{~min}$, followed by the addition of $900 \mu \mathrm{l}$ distilled $\mathrm{H}_{2} \mathrm{O}$ and a 20 -min incubation in the HFIP/water mixture. Subsequently, the solvent was evaporated from the resulting supernatant under constant stirring at room temperature for 5 days. Oligomerization was verified by dot blot assay as previously described (19).

Animals and animal treatments. To elucidate the in vivo effects of $\mathrm{A} \beta$ peptide on the retina, $\mathrm{C} 57 \mathrm{BL} / 6$ mice received a single unilateral subretinal injection of $A \beta$ peptide (Fig. 1). Briefly, 5 -month-old C57BL/6 mice were anesthetized by an intraperitoneal injection of $300 \mathrm{mg} / \mathrm{kg}$ chloral hydrate (Sangon Biotech, Shanghai, China). The pupils were dilated with $0.5 \%$ tropicamide and $0.5 \%$ phenylephrine (Santen Pharmaceutical, Osaka, Japan); $0.5 \%$ proparacaine hydrochloride (Alcon, Shanghai, China) was applied for topical anesthesia. Following complete pupillary dilation, the anesthetized animals were placed under an Nikon SMZ-1 stereoscopic microscope, and the corneas were carefully punctured through the pars plana with a 30-gauge needle to produce a hole sufficiently large enought to insert a 33-gauge blunt needle (Hamilton Co., Reno, NV, USA). The blunt needle tip was inserted through the corneal puncture and advanced into the anterior chamber. A slight resistance to the movement of the needle indicated the penetration of the retina and entrance into the subretinal matrix. The mice were divided into 3 groups as follows: i) mice injected with oligomeric $\mathrm{A} \beta(1-42)[\mathrm{OA} \beta(1-42)(1 \mathrm{nmol} / 2 \mu \mathrm{l}$, $\mathrm{n}=24)$; ii) mice injected with $\mathrm{OA} \beta(42-1)(1 \mathrm{nmol} / 2 \mu \mathrm{l}, \mathrm{n}=8)$, and iii) mice injected with $2 \mu \mathrm{l}$ of phosphate-buffered saline (PBS) (calcium- and magnesium-free, $\mathrm{n}=8$ ).
All animal experiments were performed according to the ARVO Statement for the Use of Animals in Ophthalmic and Vision Research. All surgical interventions and animal care procedures were approved by the Ethics Committee of Tongji University, Shanghai, China.

Electroretinography (ERG). Flash ERG (FERG) was recorded using an ERG recording system (APS-2000AER; Kanghua Ruiming Technology, Chongqing, China). The animals were allowed to adapt to the dark overnight and prepared for electroretinography and the scotopic electroretinogram was recorded. The animals were anesthetized with an intraperitoneal injection pf $300 \mathrm{mg} / \mathrm{kg}$ chloral hydrate (Sangon Biotech). Following pupillary dilation and the topical anesthesia of the cornea, gold loop electrodes were placed on the cornea with a drop of $2.5 \%$ hydroxypropyl methylcellulose. Subsequently, the reference electrode was placed into the mouth of the animal underneath the tongue, and a ground electrode was subcutaneously inserted into the midway of the tail. The ERG waveforms were then recorded in response to a flash at $1.125 \mathrm{~cd}^{*} \mathrm{~s} / \mathrm{m}^{2}$. The amplitude of the a-wave was measured from the baseline to the trough of the a-wave. The amplitude of the b-wave was measured from the trough of the a-wave to the peak of the $b$-wave. The amplitude of the c-wave was measured from the baseline to the peak of the c-wave.

Retinal tissue immunohistochemistry. On day 7 following surgery, the mice were terminally anesthetized and subjected to whole-body perfusion with $4 \%$ paraformaldehyde (PFA) in PBS and the whole eyes were then enucleated and fixed in 4\% PFA overnight. Only sections including the optic nerve were used for histological and immunohistochemical analyses. Sections (5- $\mu \mathrm{m}$-thick) of paraffin-embedded specimens were stained with hematoxylin and eosin (H\&E). The slides were dehydrated and placed on a coverslip.

For immunohistochemical analysis, antibody staining was performed on sections of paraffin-embedded eyes. Antibodies to RPE65 (ab67042) and p16 $6^{\mathrm{INK} 4 \mathrm{a}}$ (ab54210) were obtained from Abcam (Hong Kong, China) and used at a dilution of 1:100. The paraffin-embedded sections were heated to $60^{\circ} \mathrm{C}$ for $30 \mathrm{~min}$, and then deparaffinized and rehydrated in graded alcohol series. The paraffin-embedded sections were incubated for $1 \mathrm{~h}$ in PBS containing 5\% FCS to reduce non-specific binding, and then overnight at $4^{\circ} \mathrm{C}$ with the p16 $6^{\mathrm{INK} 4 \mathrm{a}}$ and RPE65 primary antibodies. After washing, the sections were incubated in a solution of 1:200 of goat anti-mouse 594-conjugated secondary antibody or goat anti-rabbit 488-conjugated secondary antibody (Abcam). The sections were then washed, stained for 5 min with DAPI, and washed again in PBS. The sections were then mounted and examined under a fluorescence microscope (Leica TCS SP5; Leica Microsystems, Wetzlar, Germany).

Transmission electron microscopy (TEM). For ultrastructural analysis, the enucleated eyes were dissected at the equator immediately and the posterior eye cups were fixed in $2.5 \%$ glutaraldehyde in phosphate buffer at $4^{\circ} \mathrm{C}$ overnight. The central $2 \times 2 \mathrm{~mm}$ tissue temporal to the optic nerve was post-fixed with $2 \%$ osmium tetroxide and alcohol dehydrated and embedded in epoxy resin. The ultra-thin sections were stained with lead 

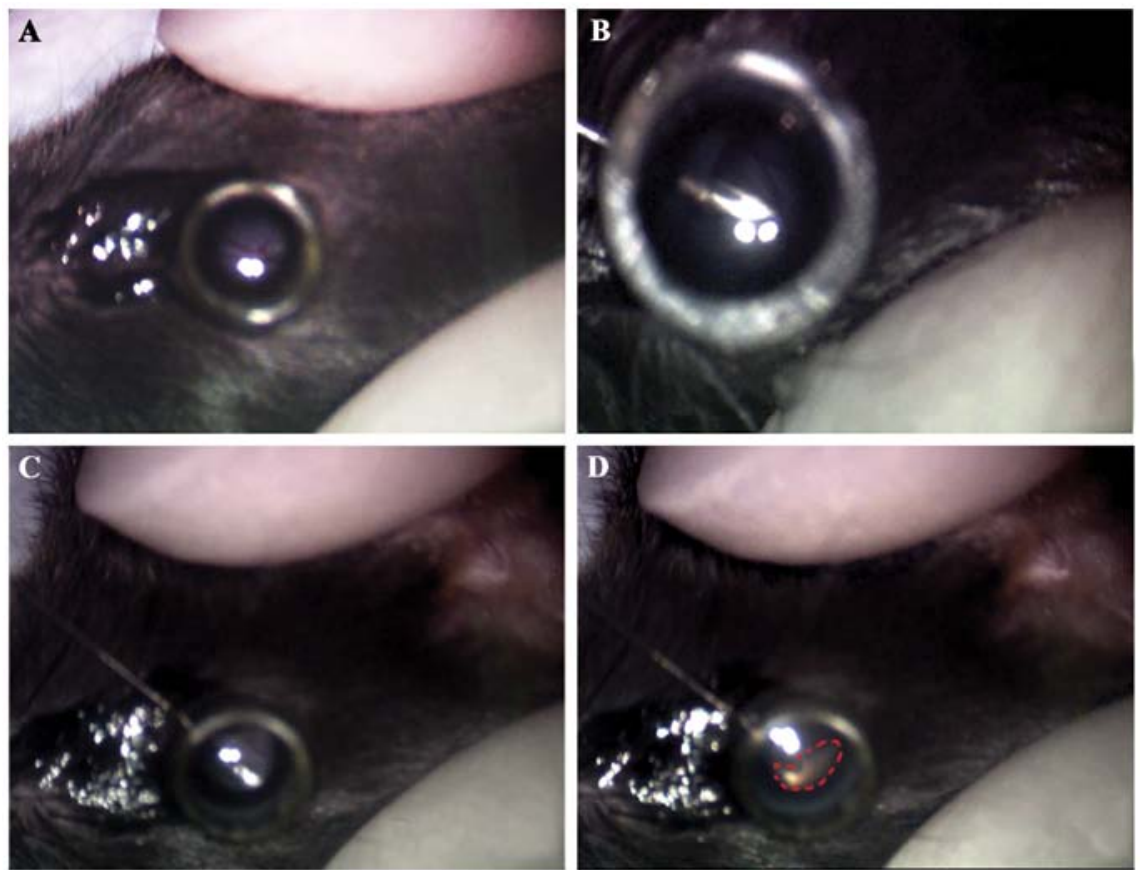

Figure 1. Subretinal injection of amyloid- $\beta(\mathrm{A} \beta)$ peptide administered to C57BL/6 mice. (A) Complete mydriasis prior to injection. The retinal blood vessel can be visualized after pupil dilation. (B) Puncture of the cornea with a 30-gauge needle. (C) Upon penetration of the retina with a 33 -gauge blunt needle, A $\beta$ peptide or phosphate-buffered saline (PBS) were delivered subretinally. (D) Formation of the retinal bleb. Visualization of the bleb indicated a successful subretinal injection, as previously described (59).

citrate and uranyl acetate, and examined under an electron microscope (CM120; Philips, Eindhoven, The Netherlands).

Fundus photography. For the funduscopic examination of the mice, confocal scanning laser ophthalmoscopy (cSLO) was performed using a device available for human fundus imaging (Spectralis HRA; Heidelberg Engineering, Heidelberg, Germany). Fundus images were captured using a 790-nm diode laser for infrared (IR) and $488 \mathrm{~nm}$ for autofluorescence (AF).

Western blot analysis. RPE-choroid preparations for western blot analysis and RT-PCR were dissected from the freshly harvested eyes and preserved at $-80^{\circ} \mathrm{C}$ until further processing. The RPE-choroid complex was sonicated in radio-immunoprecipitation assay (RIPA) buffer containing proteinase inhibitors for $15 \mathrm{~min}$. Protein content was determined by a bicinchoninic acid assay (Pierce, Rockford, IL, USA). Aliquots (50 $\mu \mathrm{g}$ of total protein) of each sample from the RPE-choroid were loaded per lane onto $10 \%$ SDS-PAGE gels for electrophoresis and then transferred onto PVDF membranes. The membranes were blocked and incubated with the primary antibody, rabbit polyclonal antibodies against p16 ${ }^{\mathrm{INK} 4 \mathrm{a}}(1: 500$; Abcam) and rabbit polyclonal antibodies against glyceraldehyde-3-phosphate dehydrogenase [GAPDH (Cat. no. ab37168), 1:1,000] overnight. The membranes were then washed and incubated with horseradish peroxidase-coupled secondary antibodies for $2 \mathrm{~h}$. The blots were washed and developed with chemiluminescence reagent. The membranes were exposed to ImageQuant LAS 4000 imaging, and densitometric analysis was performed using Photoshop CS4.0 software.

RT-PCR and real-time PCR. Total RNA was isolated using TRIzol reagent (Invitrogen, Carlsbad, CA, USA) and was then reverse transcribed into cDNA with RT Master Mix (Takara Biotechnology, Dalian, China). The expression levels of IL-8 and IL-6 were measured using quantitative PCR mix (Takara Biotechnology). The primers used for PC were as follows: IL-6 sense, 5'-TTCCATCCAGTTGCCTTCTT-3' and antisense, 5'-CATTTCCACGATTTCCCAGA-3'; IL-8 sense, 5'-CCTT GGTCTTCCTGCTTGA-3' and antisense, 5'-ATCGTTG TTCCCATCCACAT-3'. Real-time PCR was performed in a ABI7500 Real-Time PCR system (Applied Biosystems, Foster City, CA, USA). GAPDH (sense, 5'-AGCAGTCCCGTACA CTGGCAAAC-3' and antisense), 5'-TCTGTGGTGATGT AAATGTCCTCT-3' was used for normalization and the relative gene expression was expressed as the relative 'fold change' calculated using the $\Delta \Delta \mathrm{Ct}$ method.

\section{Results}

A $\beta$ peptide leads to impairment of visual function in animals. To elucidate the in vivo effects of $A \beta$ peptide on visual function, $\mathrm{C} 57 \mathrm{BL} / 6$ mice received a subretinal injection of $\mathrm{A} \beta$ peptide, and visual function was evaluated by ERG on day 7 postinjection. Photoreceptors are the source of the negative-going a-wave $(21,22)$. Rod bipolar cells are the source of the b-wave in the dark-adapted retina (23-25). RPE cells are the source of the positive-going c-wave (26). Representative waveforms of the maximal ERG scotopic response evoked by a single flash at $1.125 \mathrm{~cd}^{*} \mathrm{~s} / \mathrm{m}^{2}$ are illustrated in Fig. 2A. No significant differences were observed between the $A \beta(42-1)$-injected mice and the PBS control mice. However, a moderate but significant decrease in a-, b- and c-wave amplitude was detected in the $A \beta(1-42)$-injected mice (Fig. $2 A$ and $B$ ). These results indicated that the subretinal injection of $A \beta(1-42)$ induced an impairment of visual function in the animals. 
$\mathbf{A}$

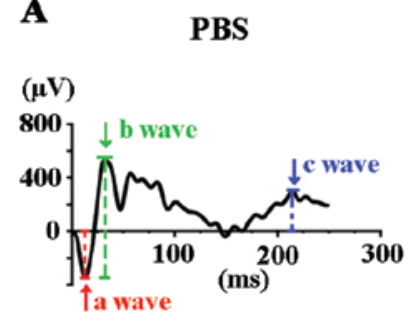

$\mathbf{A} \beta(42-1)$

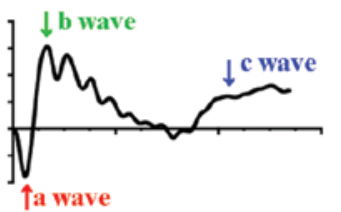

Aß(1-42)

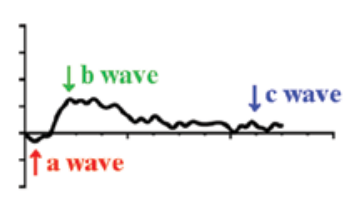

B

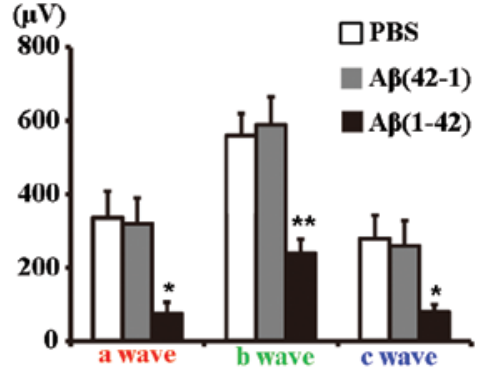

Figure 2. Evaluation of visual function in amyloid- $\beta$ (A $\beta$ )-injected mice. (A) Waveforms of the maximal electroretinography (ERG) response evoked by a flash at $1.125 \mathrm{~cd} * \mathrm{~s} / \mathrm{m}^{2}$ in mice. (B) Amplitudes of scotopic ERG responses at $1.125 \mathrm{~cd}$ " $\mathrm{s} / \mathrm{m}^{2}$ flash intensity were recorded and presented in the bar chart. This result showed significantly decreased a-, b- and c-wave amplitudes in the A $\beta(1-42)$-injected mice when compared to the phosphate-buffered saline (PBS) control or reverse peptide group $\left[\mathrm{A} \beta(1-42), \mathrm{n}=24\right.$; PBS, $\mathrm{n}=8$; reverse peptide $\mathrm{A} \beta(42-1), \mathrm{n}=8 ;{ }^{*} \mathrm{P}<0.05 ;{ }^{* * *} \mathrm{P}<0.01$, Student's t-test].

A

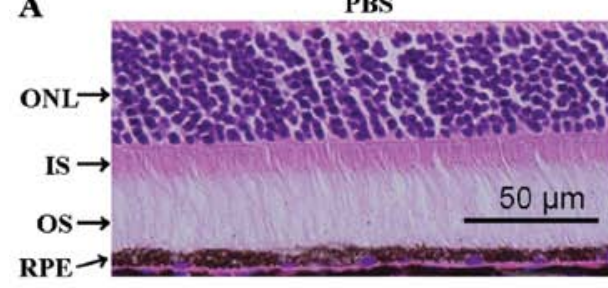

PBS

B

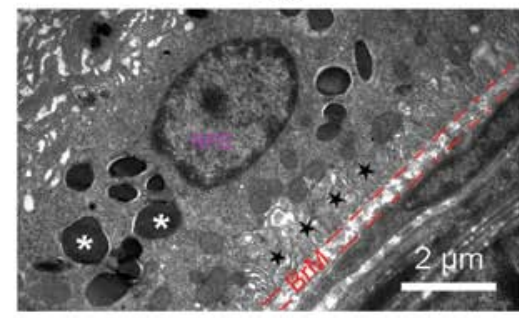

AB(42-1)

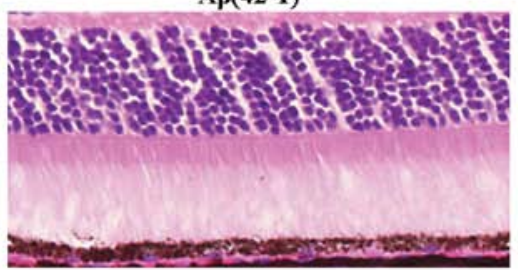

AB(42-1)

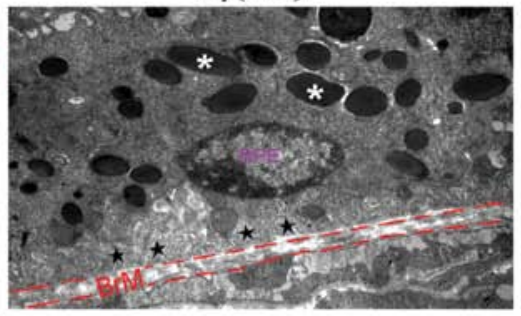

Aß(1-42)

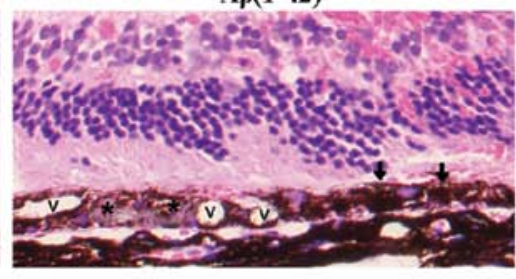

$\mathrm{A} \beta(\mathbf{1 - 4 2 )}$

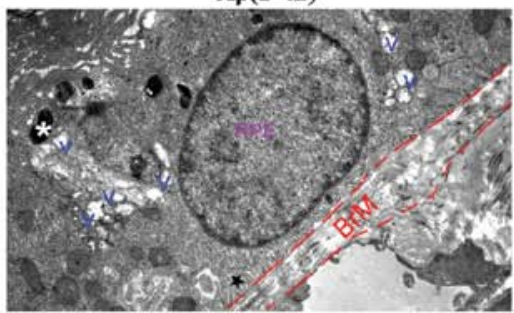

Figure 3. Histopathology of retinal degeneration and deleterious alterations of the structure of the retinal pigment epithelium (RPE) in amyloid- $\beta$ (A $\beta$ ) peptideinjected mice. (A) Hematoxylin and eosin (H\&E)-stained paraffin sections of the RP/neural retina. Signs of retinal degeneration, including extensive vacuolation (V symbol), hyperpigmentation (arrow), hypopigmentation (black asterisk) and thickness of Bruch's membrane (BrM), were observed in the $\mathrm{A} \beta(1-42)$-injected mice. ONL, outer nuclear layer; IS, inner segment; OS, outer segment. (B) Transmission electron microscopy (TEM) of the interface between the RPE and BrM in mice. RPE basal infoldings (black star) and BrM thickness appear normal in the A $\beta(42-1)$-injected eye (middle panel) compared with the phosphate-buffered saline (PBS)-injected control mice (left panel). By contrast, in the A $\beta(1-42)$-injected mice, the loss of pigmented granules, obvious thickening of the BrM, the loss of normal basal infoldings and the formation of autophagic vacuoles were observed. White asterisk, pigmented granules; black star, normal basal infoldings; $\mathrm{V}$, vacuoles.

A $\beta$ induces retinal degeneration and ultrastructural alterations in the outer retina. To demonstrate the deleterious effects of $A \beta(1-42)$ on the retina, we compared its effects on retinal histology and RPE structure with those of PBS and the inactive reverse peptide $\mathrm{A} \beta(42-1)$. The H\&E-stained sections of RPE/neural retina were examined under a microscope (Fig. 3A). The mice injected with PBS or the reverse peptide showed a normal appearance of retinal sections (Fig. 3A, left and middle panels). By contrast, degenerative alterations, including extensive vacuolation ( $\mathrm{V}$ symbol), hyperpigmentation (arrow), hypopigmentation (asterisk) and thickness of the BrM, were observed in the outer retina of the $\mathrm{A} \beta(1-42)$-injected mice (Fig. 3A, right panel).

Subsequently, the RPE structures were examined by TEM. The PBS- and A $\beta(42-1)$-injected mice showed normal structures of the RPE, well-developed RPE infoldings and a consistent thickness of the BrM (Fig. 3B, left and middle panels). In the $A \beta(1-42)$-injected mice, the RPE cells were highly vacuolated with membranous debris, the normal basal infoldings were replaced by amorphous material deposits, the number of pigment granules decreased and the BrM was thickened (Fig. 3B, right panel). Taken together, the results from histopathological analysis and TEM demonstrated that the $A \beta(1-42)$-injected mice developed some degenerative alterations on the neural retina layer, the RPE and BrM, which are similar to some of the morphological characteristics of patients with AMD (27).

RPE cell senescence is induced by the subretinal injection of $A \beta$ peptide. We then investigated whether the subretinal injection of $A \beta(1-42)$ induces RPE cell senescence. cSLO, a clinical imaging method, is used to examine the fundus autofluorescence (FAF) pattern as a means of assessing the health of the RPE in AMD. Therefore, funduscopic examination was used to assess $\mathrm{RPE}$ alterations/senescence in vivo. IR-cSLO revealed that the $\mathrm{A} \beta(1-42)$-injected mice developed an increase in the number of drusen-like lesions characterized by irregularly shaped bright regions (Fig. 4A, right panel), and the increased granular 
$\mathbf{A}$

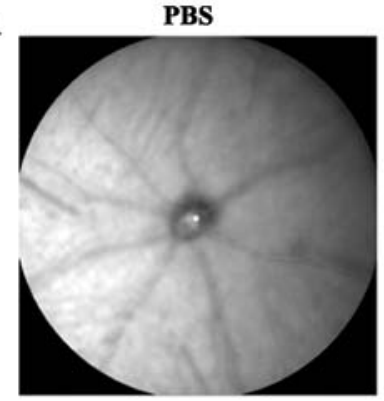

B

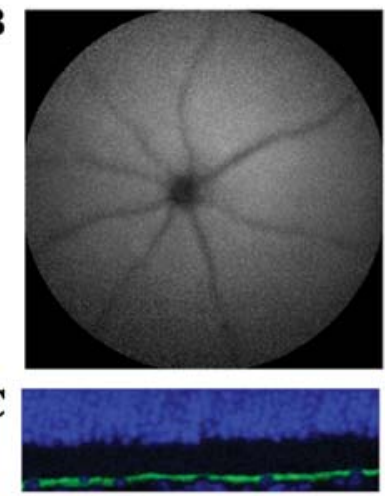

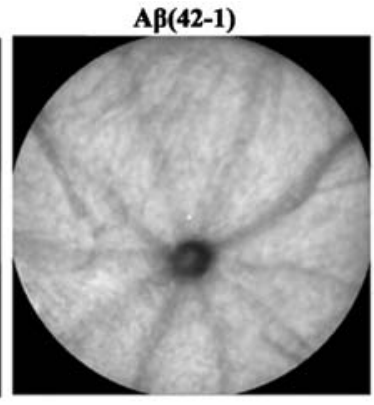
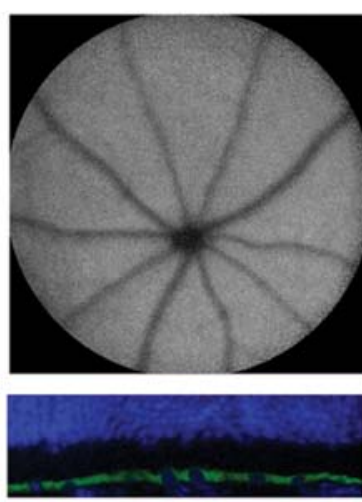
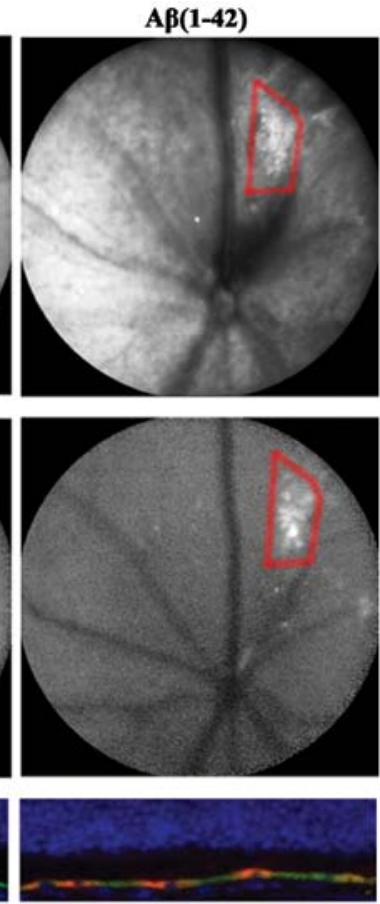

D
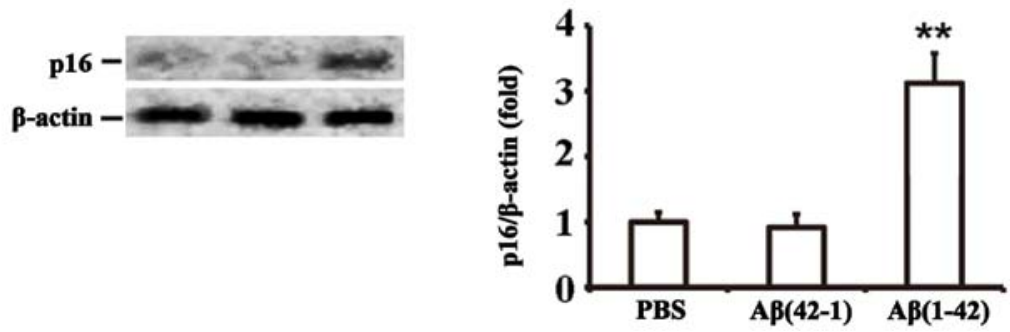

Figure 4. Evaluation of senescence of cells of the retinal pigment epithelium (RPE) in amyloid- $\beta$ (A $\beta$ ) peptide-injected mice. (A) Near-infrared (790 nm) autofluorescence (AF) imaging of the fundus. (B) Blue (488 nm) AF imaging of the fundus. (C) Neuroretinal sections double-immunostained with RPE65 (green) and p16 $6^{\text {INK4a }}$ (red). (D) Evaluation of p16 ${ }^{\text {INK4a }}$ expression by western blot analysis. $[A \beta(1-42), n=20$; phosphate-buffered saline $($ PBS $)$, n=10; reverse peptide $A \beta(42-1)$, $\mathrm{n}=10 ;{ }^{* *} \mathrm{P}<0.01$, Student's t-test].

autofluorescent spots were observed by AF-cSLO in almost the same areas (Fig. 4B, right panel). By contrast, no significant distribution of fluorophores was observed in the ocular fundus of the PBS- or A $\beta(42-1)$-injected mice (Fig. 4A and B). The analysis of cell senescence on RPE/neural retinal sections by $16^{\text {INK4a }}$ staining confirmed that $A \beta(1-42)$ induced RPE cell senescence in the mice on day 7 post-injection (Fig. 4C, right panel). However, in the retinal sections of the PBS- or $\mathrm{A} \beta(42-1)$-injected mice, no $\mathrm{p} 16^{\mathrm{INK} 4 \mathrm{a}}$-positive RPE cells were detected (Fig. 4C, left and middle panels). Subsequently, the expression level of $\mathrm{p} 16^{\mathrm{INK} 4 \mathrm{a}}$ in RPE cells was determined by western blot analysis; the injection of $A \beta(1-42)$ significantly increased $\mathrm{p} 16^{\text {INK4a }}$ expression by $(3.12 \pm 0.46)$-fold compared with the injection of the reverse peptide or PBS (Fig. 4D). Taken together, these data strongly suggest that $A \beta(1-42)$ significantly induces RPE cell senescence in the retinas of mice.

mRNA expression of IL-6 and IL-8 is upregulated following the subretinal injection of $A \beta(1-42)$ peptide. Hallmarks of inflammation, including elevated IL-6 and IL-8 expression, are significantly associated with the severity of AMD. Recent evidence indicates that cellular senescence is accompanied by a marked increase in the secretion of 40-80 factors, which has been termed the SASP (42). The key SASP factors, such as
IL-6 and IL-8, are known to stimulate chronic inflammation in age-related diseases (42). Thus, to determine whether the subretinal injection of $A \beta$ alters SASP gene expression in RPE cells, the RPE-choroid layer was isolated and IL-6 and IL-8 mRNA expression was examined by RT-PCR. A $\beta(1-42)$ injection significantly increased the mRNA expression of IL-6 (6.8 \pm 0.8 -fold, $\mathrm{P}<0.05)$ and IL-8 (3.7 \pm 1.2 -fold, $\mathrm{P}<0.05)$, compared with PBS-injected group (Fig. 5), whereas the injection of $A \beta(42-1)$ did not induce any significant changes in the mRNA expression of IL-6 and IL-8, compared with the PBS-injected group (Fig. 5).

\section{Discussion}

The main results of the present study were as follows: i) the subretinal injection of $A \beta(1-42)$ impaired the visual function of mice (Fig. 2); ii) $A \beta(1-42)$-injected mice developed some degenerative alterations on the retina and RPE cells (Fig. 3); iii) signs of RPE cell senescence, including increased FAF and the expression of the senescence-associated marker, p16 ${ }^{\mathrm{INK} 4 \mathrm{a}}$, were observed in the $A \beta(1-42)$-injected mice (Fig. 4); iv) the major SASP factors, such as IL-6 and IL-8, were significantly upregulated in the RPE-choroid of $A \beta(1-42)$-injected mice (Fig. 5). Taken together, our results demonstrate a causal 


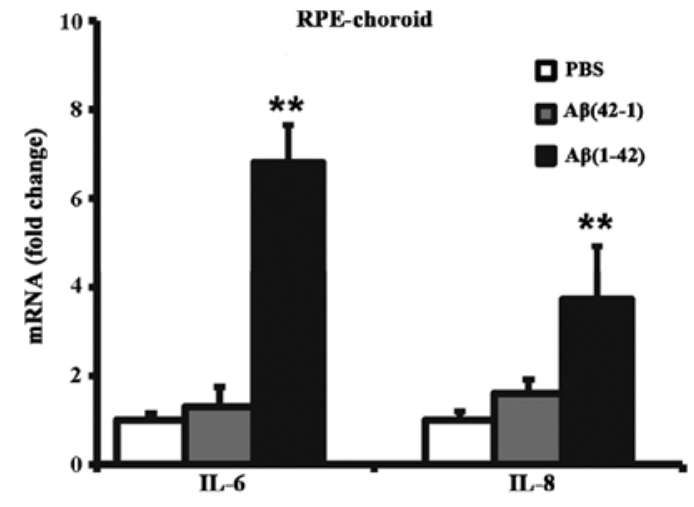

Figure 5. Analysis of cytokine expression in the retinal pigment epithelium (RPE)-choroid. In the A $\beta(1-42)$-injected group, interleukin (IL)-6 and IL-8 mRNA expression was significantly increased, compared to that in the mice injected with phosphate-buffered saline (PBS) or the reverse peptide. [A $\beta(1-42)$, $\mathrm{n}=20$; PBS, $\mathrm{n}=10$; reverse peptide $\mathrm{A} \beta(42-1), \mathrm{n}=10 ;{ }^{* *} \mathrm{P}<0.01$, Student's t-test].

connection between $A \beta$ peptide deposition and the appearance of senescent RPE cells, and suggest that the subretinal injection of $\mathrm{A} \beta$ induces senescence-associated chronic inflammation. Our data also suggest that $A \beta$-injected mice represent a useful animal model of AMD.

The electroretinogram is a non-invasive method to evaluate the function of specific layers of the retina. The negative-going a-wave and the positive-going $b$-wave originate from photoreceptors and rod bipolar cells, respectively (21-25), whereas the sources of the positive-going c-wave are the RPE and retinal glial cells (26). In our study, in $A \beta(1-42)$-injected mice, there was a statistically significant decrease in the a-, b- and c-wave amplitude compared to the control group (Fig. 2). Similar findings of decreased ERG response have been reported in APP/ PS1 transgenic mice, which presented with accumulated $A \beta$ deposition in the retina (28). Therefore, the decreased ERG response or the impaired visual function may be secondary to the retinal degenerative alterations induced by the subretinal injection of $A \beta(1-42)$.

Consistent with the decreased ERG response, microscopic examination revealed severe degenerative alterations in the retinas of the $A \beta(1-42)$-injected mice, including the loss of inner and outer segments, extensive vacuolation, RPE hypopigmentation and thickness of the BrM (Fig. 3A). These data are consistent with those of other in vivo studies, which demonstrated that the subretinal or intravitreal injection of $A \beta$ peptide induced progressive retinal degeneration and the disorganization of RPE cells $(7,20,29)$.

In $A \beta(1-42)$-injected mice, ultrastructural analysis by TEM revealed that the RPE cells had multiple vacuoles in the cytoplasm, and that basal infoldings were fewer or absent (Fig. 3B). The RPE appears to be a specific target of $A \beta$. The subretinal injection of $A \beta(1-42)$ induced a loss of pigmentation and RPE hypertrophy (Fig. 2A). Intravitreal injections of $A \beta$ peptide have been shown to induce a comparable magnitude of gene expression changes in the RPE-choroid compared with the neuroretina (7), indicating that the RPE plays a major role in response to $A \beta$ peptide. The most obvious ultrastructural sign of RPE injury was the loss of basolateral infoldings, which are an established marker of epithelial cell injury (30). Vacuole formation was used as a second sign of RPE injury, as cytoplasmic vacuoles have been identified in the RPE that overlie drusen deposits (31). Of note, in a study on colon cancer cells, Sox2induced autophagy inhibited cell proliferation and enhanced cellular senescence, suggesting that the formation of autophagic vacuoles is involved in cellular senescence (32). To the best of our knowledge, our study is the first to demonstrate that the subretinal injection of $A \beta$ peptide induced two marked ultrastructural alterations, including the loss of basal infoldings and the formation of intracellular vacuoles, in RPE cells (Fig. 3B).

It has been suggested that $A \beta(1-42)$ plays a central role in the pathogenesis of $\mathrm{AD}$ as a mediator of oxidative stress (33). A previous study investigated the in vitro effects of $A \beta(1-42)$ on RPE cells and found that it induced an increase in reactive oxygen species (ROS) production and caused mitochondrial dysfunction (29). Considering that persistent and sublethal oxidative stress accelerates cellular senescence (34), the effects of $A \beta(1-42)$ on RPE cell senescence were evaluated in the present study. First, the increased granular autofluorescent spots were observed by cSLO in the fundus of $A \beta(1-42)$-injected mice (Fig. 4A and B). During cell senescence, autofluorescent lysosomal storage bodies known as lipofuscins or age-pigments accumulate in many post-mitotic types of cells $(35,36)$. It is well known that the RPE accumulates massive amounts of autofluorescent lysosomal storage bodies (lipofuscins) during cell senescence (37-39). The formation of fundus autofluroscence in human eyes is associated with RPE atrophy and the progression to advanced AMD (40). Lipofuscins contained in the RPE are the main source of FAF; it has been reported that FAF detected at $488 \mathrm{~nm}$ excitation with a cSLO is largely attributable to RPE lipofuscins $(40,41)$. Therefore, increased fundus AF detected by cSLO may be a signal of RPE cell senescence (Fig. 4A and B). Subsequently, the increase in p16 ${ }^{\text {INK4a }}$ expression was proved by immunostaining (Fig. 4C) and western blot analysis (Fig. 4D), indicating that the $\mathrm{A} \beta(1-42)$-induced RPE senescence is regulated by $16^{\mathrm{INK} 4 \mathrm{a}}$. This finding is consistent with our previous in vitro study, indicating that $A \beta$ peptide is involved in the senescence of RPE cells (19). It is also consistent with the results of other studies, suggesting that $\mathrm{A} \beta$ peptides induce endothelial cells, astrocytes and neurons to enter senescence $(15,17,18)$.

We observed a significant overexpression of IL-6 and IL-8 in the RPE-choroid of A $\beta(1-42)$-injected mouse eyes (Fig. 5). Senescent cells contribute to aging and age-related disease by generating a low-grade inflammatory state (42). Our results suggested that cellular senescence may promote inflammation, which is consistent with the findings of other studies demonstrating an increased production of IL- 6 and IL- 8 by senescent fibroblasts and epithelial cells $(43,44)$. IL-6 and IL-8 may stimulate angiogenesis, enforce macrophage function and induce innate immune responses (45). Moreover, it has been reported that IL- 6 and IL-8 reinforce senescent growth arrest $(46,47)$. Kuilman et al $(47)$ verified that the suppression of IL-8, IL-6 or its cognate receptor, IL-6R, was sufficient to allow these cells to re-enter the cell cycle and proliferate, supporting the possibility that these cytokines function in vivo to promote cellular senescence. In addition, the aqueous humor of patients with AMD contains higher concentrations of IL-6 and IL-8 (48). We focused our attention on these cytokines as they can act not only as pro-inflammatory cytokines, but also as potent inducers of growth arrest (49). Overall, we conclude 
that $A \beta$-induced senescent RPE cells may produce high levels of IL-6 and IL-8, which are both required to amplify and sustain the inflammatory network and senescence.

AMD is an age-related chronic inflammatory disease $(50,51)$. Our previous study (19) and the present study indicate that A $\beta$-induced senescent RPE cells may constitute a link between chronic inflammation and neuroretinal degeneration. Senescence-causing inducers, such as DNA damage, protein aggregation and increased ROS may activate the p53 and p16 ${ }^{\mathrm{INK} 4 \mathrm{a}}$ pathways that initiate a senescence response (52-56). Once initiated, senescence becomes fully established and is irreversible. Subsequently, the senescent cells affect the tissue microenvironment by secreting pro-inflammatory cytokines, chemokines and proteases $(12,57)$. It has been reported that the clearance of p16 ${ }^{\text {INK4a }}$-positive senescent cells prevents age-related disorders and maximizes a healthy lifespan (58). Thus, the modulation of cellular senescence, including the elimination of selected senescent cells, the clearance of senescence inducers, such as $\mathrm{A} \beta$ peptide deposition, the prevention of cellular senescence or affecting the secretory phenotype may reduce age-related sterile chronic inflammation in AMD.

\section{Acknowledgements}

We would like to thank the Biochemistry and Molecular Biology Institute of Shanghai Tenth People's Hospital and are grateful for their technological support. This study was supported by grants from the Outstanding Youths Program of Shanghai Tongji University (No. 1501219084), the Science and Technology Commission of Shanghai (No. 11JC1409900) and the National High Technology Research and Development Program of China (863 program, No. S2010GR0002).

\section{References}

1. Sarks SH: Drusen patterns predisposing to geographic atrophy of the retinal pigment epithelium. Aust J Ophthalmol 10: 91-97, 1982.

2. Bressler NM, Silva JC, Bressler SB, Fine SL and Green WR: Clinicopathologic correlation of drusen and retinal pigment epithelial abnormalities in age-related macular degeneration. 1994. Retina 25: 130-142, 2005.

3. Dentchev T, Milam AH,Lee VM, Trojanowski JQ and Dunaief JL: Amyloid-beta is found in drusen from some age-related macular degeneration retinas, but not in drusen from normal retinas. Mol Vis 9: 184-190, 2003

4. Johnson LV, Leitner WP, Rivest AJ, Staples MK, Radeke MJ and Anderson DH: The Alzheimer's A beta -peptide is deposited at sites of complement activation in pathologic deposits associated with aging and age-related macular degeneration. Proc Natl Acad Sci USA 99: 11830-11835, 2002.

5. Kurji KH, Cui JZ, Lin T, et al: Microarray analysis identifies changes in inflammatory gene expression in response to amyloid-beta stimulation of cultured human retinal pigment epithelial cells. Invest Ophthalmol Vis Sci 51: 1151-1163, 2010.

6. Cao L, Liu C, Wang F and Wang H: SIRT1 negatively regulates amyloid-beta-induced inflammation via the NF-kappaB pathway. Braz J Med Biol Res 46: 659-669, 2013.

7. Liu RT, Gao J, Cao S, et al: Inflammatory mediators induced by amyloid-beta in the retina and RPE in vivo: implications for inflammasome activation in age-related macular degeneration. Invest Ophthalmol Vis Sci 54: 2225-2237, 2013.

8. Ding JD, Johnson LV, Herrmann R, et al: Anti-amyloid therapy protects against retinal pigmented epithelium damage and vision loss in a model of age-related macular degeneration. Proc Natl Acad Sci USA 108: E279-E287, 2011.

9. Buschini E, Piras A, Nuzzi R and Vercelli A: Age related macular degeneration and drusen: neuroinflammation in the retina. Prog Neurobiol 95: 14-25, 2011.
10. Coppé JP, Patil CK, Rodier F, et al: Senescence-associated secretory phenotypes reveal cell-nonautonomous functions of oncogenic RAS and the p53 tumor suppressor. PLoS Biol 6: 2853-2868, 2008.

11. Kumar S, Millis AJ and Baglioni C: Expression of interleukin 1-inducible genes and production of interleukin 1 by aging human fibroblasts. Proc Natl Acad Sci USA 89: 4683-4687, 1992.

12. Campisi J: Senescent cells, tumor suppression, and organismal aging: good citizens, bad neighbors. Cell 120: 513-522, 2005.

13. Ben-Porath I and Weinberg RA: The signals and pathways activating cellular senescence. Int J Biochem Cell Biol 37: 961-976, 2005.

14. Lombard DB, Chua KF, Mostoslavsky R, Franco S, Gostissa M and Alt FW: DNA repair, genome stability, and aging. Cell 120: 497-512, 2005.

15. He N, Jin WL, Lok KH, Wang Y, Yin $M$ and Wang ZJ: Amyloid- $\beta(1-42)$ oligomer accelerates senescence in adult hippocampal neural stem/progenitor cells via formylpeptide receptor 2. Cell Death Dis 4: e924, 2013.

16. Golde TE and Miller VM: Proteinopathy-induced neuronal senescence: a hypothesis for brain failure in Alzheimer's and other neurodegenerative diseases. Alzheimers Res Ther 1: 5 , 2009.

17. Bhat R, Crowe EP, Bitto A, et al: Astrocyte senescence as a component of Alzheimer's disease. PLoS One 7: e45069, 2012.

18. Donnini S, Solito R, Cetti E, et al: Abeta peptides accelerate the senescence of endothelial cells in vitro and in vivo, impairing angiogenesis. FASEB J 24: 2385-2395, 2010.

19. Cao L, Wang H, Wang F, Xu D, Liu F and Liu C: A $\beta$-induced senescent retinal pigment epithelial cells create a proinflammatory microenvironment in AMD. Invest Ophthalmol Vis Sci 54: 3738-3750, 2013.

20. Bruban J, Maoui A, Chalour N, et al: CCR2/CCL2mediated inflammation protects photoreceptor cells from amyloid-beta-induced apoptosis. Neurobiol Dis 42: 55-72, 2011.

21. Hood DC and Birch DG: A quantitative measure of the electrical activity of human rod photoreceptors using electroretinography. Vis Neurosci 5: 379-387, 1990.

22. Penn RD and Hagins WA: Signal transmission along retinal rods and the origin of the electroretinographic a-wave. Nature 223: 201-204, 1969.

23. Robson JG and Frishman LJ: Response linearity and kinetics of the cat retina: the bipolar cell component of the dark-adapted electroretinogram. Vis Neurosci 12: 837-850, 1995.

24. Tian N and Slaughter MM: Correlation of dynamic responses in the ON bipolar neuron and the b-wave of the electroretinogram. Vision Res 35: 1359-1364, 1995.

25. Robson JG, Maeda H, Saszik SM and Frishman LJ: In vivo studies of signaling in rod pathways of the mouse using the electroretinogram. Vision Res 44: 3253-3268, 2004.

26. Hanitzsch R and Lichtenberger T: Two neuronal retinal components of the electroretinogram c-wave. Doc Ophthalmol94: 275-285, 1997.

27. Green WR and Enger C: Age-related macular degeneration histopathologic studies. The 1992 Lorenz E. Zimmerman Lecture. Ophthalmology 100: 1519-1535, 1993.

28. Perez SE, Lumayag S, Kovacs B, Mufson EJ and Xu S: Beta-amyloid deposition and functional impairment in the retina of the APPswe/PS1DeltaE9 transgenic mouse model of Alzheimer's disease. Invest Ophthalmol Vis Sci 50: 793-800, 2009.

29. Bruban J, Glotin AL, Dinet V, et al: Amyloid-beta(1-42) alters structure and function of retinal pigmented epithelial cells. Aging Cell 8: 162-177, 2009.

30. Drüeke T, Hennessen U, Nabarra B, et al: Ultrastructural and functional abnormalities of intestinal and renal epithelium in the SHR. Kidney Int 37: 1438-1448, 1990.

31. Anderson DH, Mullins RF, Hageman GS and Johnson LV: A role for local inflammation in the formation of drusen in the aging eye. Am J Ophthalmol 134: 411-431, 2002.

32. Cho YY, Kim DJ, Lee HS, et al: Autophagy and cellular senescence mediated by Sox 2 suppress malignancy of cancer cells. PLoS One 8: e57172, 2013.

33. Butterfield DA and Boyd-Kimball D: Amyloid beta-peptide(1-42) contributes to the oxidative stress and neurodegeneration found in Alzheimer disease brain. Brain Pathol 14: 426-432, 2004.

34. Yu AL, Fuchshofer R, Kook D, Kampik A, Bloemendal H and Welge-Lüssen U: Subtoxic oxidative stress induces senescence in retinal pigment epithelial cells via TGF-beta release. Invest Ophthalmol Vis Sci 50: 926-935, 2009. 
35. Katz ML, Wendt KD and Sanders DN: RPE65 gene mutation prevents development of autofluorescence in retinal pigment epithelial phagosomes. Mech Ageing Dev 126: 513-521, 2005.

36. Rawes V, Kipling D, Kill IR and Faragher RG: The kinetics of senescence in retinal pigmented epithelial cells: a test for the telomere hypothesis of ageing? Biochemistry (Mosc) 62: 1291-1295, 1997.

37. Feeney-Burns L, Hilderbrand ES and Eldridge S: Aging human RPE: morphometric analysis of macular, equatorial, and peripheral cells. Invest Ophthalmol Vis Sci 25: 195-200, 1984.

38. Katz ML and Robison WG Jr: Age-related changes in the retinal pigment epithelium of pigmented rats. Exp Eye Res 38: 137-151, 1984.

39. Wing GL, Blanchard GC and Weiter JJ: The topography and age relationship of lipofuscin concentration in the retinal pigment epithelium. Invest Ophthalmol Vis Sci 17: 601-607, 1978.

40. Holz FG, Bindewald-Wittich A, Fleckenstein M, Dreyhaupt J, Scholl HP and Schmitz-Valckenberg S; FAM-Study Group: Progression of geographic atrophy and impact of fundus autofluorescence patterns in age-related macular degeneration. Am J Ophthalmol 143: 463-472, 2007.

41. Sparrow JR, Hicks D and Hamel CP: The retinal pigment epithelium in health and disease. Curr Mol Med 10: 802-823, 2010.

42. Freund A, Orjalo AV, Desprez PY and Campisi J: Inflammatory networks during cellular senescence: causes and consequences. Trends Mol Med 16: 238-246, 2010.

43. Tsuji T, Aoshiba K and Nagai A: Alveolar cell senescence exacerbates pulmonary inflammation in patients with chronic obstructive pulmonary disease. Respiration 80: 59-70, 2010.

44. Dagouassat M, Gagliolo JM, Chrusciel S, et al: The cyclooxygenase-2-prostaglandin E2 pathway maintains senescence of chronic obstructive pulmonary disease fibroblasts. Am J Respir Crit Care Med 187: 703-714, 2013.

45. Sparmann A and Bar-Sagi D: Ras-induced interleukin-8 expression plays a critical role in tumor growth and angiogenesis. Cancer Cell 6: 447-458, 2004.

46. Acosta JC, O'Loghlen A, Banito A, et al: Chemokine signaling via the CXCR2 receptor reinforces senescence. Cell 133: 1006-1018, 2008.

47. Kuilman T,Michaloglou C,VredeveldLC, etal:Oncogene-induced senescence relayed by an interleukin-dependent inflammatory network. Cell 133: 1019-1031, 2008.
48. Jonas JB, Tao Y, Neumaier M and Findeisen P: Cytokine concentration in aqueous humour of eyes with exudative age-related macular degeneration. Acta Ophthalmol 90: e381-e388, 2012

49. Hong DS, Angelo LS and Kurzrock R: Interleukin-6 and its receptor in cancer: implications for translational therapeutics. Cancer 110: 1911-1928, 2007.

50. Parmeggiani F, Romano MR, Costagliola C, et al: Mechanism of inflammation in age-related macular degeneration. Mediators Inflamm 2012: 546786, 2012.

51. Parmeggiani F, Sorrentino FS, Romano MR, et al: Mechanism of inflammation in age-related macular degeneration: an up-to-date on genetic landmarks. Mediators Inflamm 2013: 435607, 2013.

52. Jeyapalan JC and Sedivy JM: Cellular senescence and organismal aging. Mech Ageing Dev 129: 467-474, 2008.

53. Ksiazek K, Mikula-Pietrasik J, Olijslagers S, Jörres A, von Zglinicki T and Witowski J: Vulnerability to oxidative stress and different patterns of senescence in human peritoneal mesothelial cell strains. Am J Physiol Regul Integr Comp Physiol 296: R374-R382, 2009.

54. Weyemi U, Lagente-Chevallier O, Boufraqech M, et al: ROS-generating NADPH oxidase NOX4 is a critical mediator in oncogenic H-Ras-induced DNA damage and subsequent senescence. Oncogene 31: 1117-1129, 2012.

55. Sitte N, Merker K, Von Zglinicki T, Grune T and Davies KJ: Protein oxidation and degradation during cellular senescence of human BJ fibroblasts: part I - effects of proliferative senescence. FASEB J 14: 2495-2502, 2000.

56. Rayess H, Wang MB and Srivatsan ES: Cellular senescence and tumor suppressor gene p16. Int J Cancer 130: 1715-1725, 2012.

57. Campisi J and d'Adda di Fagagna F: Cellular senescence: when bad things happen to good cells. Nat Rev Mol Cell Biol 8: 729-740, 2007.

58. Baker DJ, Wijshake T, Tchkonia T, et al: Clearance of p16 ${ }^{\text {Ink4a }}$-positive senescent cells delays ageing-associated disorders. Nature 479: 232-236, 2011.

59. Timmers AM, Zhang H, Squitieri A and Gonzalez-Pola C: Subretinal injections in rodent eyes: effects on electrophysiology and histology of rat retina. Mol Vis 7: 131-137, 2001. 